\title{
PENGARUH PENGGUNAAN MODEL PEMBELAJARAN EXAMPLES NON-EXAMPLES TERHADAP HASIL BELAJAR MENULIS TEKS BERITA PADA SISWA KELAS VIII SMPN 14 KOTA TANGERANG
}

\author{
Agus Sulaeman ${ }^{1}$ \& Ariyana $^{2}$ \\ 1,2Universitas Muhammadiyah Tangerang \\ Jln. Perintis Kemerdekaan I No. 3, Babakan, Kota Tangerang, Banten, Indonesia \\ Email: sultanwahyu13@gmail.com, ariyana.mpd@gmail.com
}

\begin{abstract}
Abstrak
Tujuan penelitian ini untuk mengetahui pengaruh penggunaan model examples non examples pada siswa kelas VII SMPN 14 Kota Tangerang. Metode yang digunakan dalam penelitian ini adalah metode quasi eksperimen dengan melakukan pretes dan postes dua kelompok. Jenis metode penelitian eksperimen ini menggunakan disain penelitian Nonequivalent Control Group Design. Dimana kelas eksperimen yang diberi perlakuan dan kelas kontrol tidak diberi perlakuan. Nonequivalent Control Group Design ini hampir sama dengan pretest dan postest kontrol group desain, hanya pada desain ini kelompok eksperimen maupun kontrol tidak dipilih secara random. Teknik pengumpulan data menggunakan tes. Teknik analisis data dimulai dari uji normalitas, uji homogenitas, dan dilanjutkan uji hipotesis. Terdapat perbedaan hasil belajar menulis teks berita antara siswa yang diberi model pembelajaran examples non-examples dengan siswa yang tidak diberi model pembelajaran examples non-examples dan dibuktikan dengan hasil pengujian hipotesis yaitu pretes pada kelas kontrol dan eksperimen $\mathrm{Ho}$ diterima $\mathrm{H} 1$ ditolak, dapat disimpulkan bahwa thitung lebih kecil ttabel ( 0,42 lebih kecil 2,0022) maka pada pretes tidak memiliki perbedaan hasil belajar yang signifikan, dan hasil hipotesis postes pada kelas kontrol dan kelas eksperimen yaitu $\mathrm{H} 1$ diterima Ho ditolak karena thitung lebih besar ttabel = 3,05 lebih besar 2,0022. Maka dapat dinyatakan bahwa pemberian postes pada kelas kontrol yang tidak mendapatkan perlakukan dan kelas eksperimen mendapatkan perlakuan dengan menggunakan model pembelajaran examples non-examples menunjukkan perbedaan hasil belajar yang sangat signifikan.
\end{abstract}

Kata kunci: model pembelajaran examples non-examples, menulis teks berita

\section{THE INFLUENCE OF USING LEARNING MODELS OF EXAMPLES NON-EXAMPLES OF LEARNING OUTCOMES WRITING NEWS TEXTS FOR STUDENTS OF CLASS VIII SMPN 14 TANGERANG CITY}

\begin{abstract}
The objective of this research was to determine the effect of the use of examples non examples models in class VII students of Class VIII SMPN 14 Tangerang City the method used in this study was the quasi experimental method by pretest and posttest two groups. This type of experimental research method uses the Nonequivalent Control Group Design research design. Where the experimental class is treated and the control class is not treated. The Nonequivalent Control Group Design is almost the same as the pretest and postest control of the design group, only in this
\end{abstract}


design the experimental and control groups are not randomly selected. Data collection techniques using tests. The data analysis technique starts from the normality test, homogeneous test, and continues the hypothesis test. There are differences in learning outcomes of writing news texts between students who were given examples non-examples learning models with students who were not given examples non-examples learning and evidenced by the results of hypothesis testing, namely the pretest in the control class and the $\mathrm{Ho}$ accepted $\mathrm{H}_{1}$ experiment were rejected, it can be concluded that tcount $<$ ttable $(0.41<2.0021)$ then the pretest did not have a significant difference in learning outcomes, and the results of the posttest hypothesis on the control class and experimental class were $\mathrm{H} 1$ accepted $\mathrm{Ho}$ was rejected because thitung $>\mathrm{t}$ table $=3.03>2.0021$, then it can be stated that the giving of posttest in the control class that did not get treatment and the experimental class to get treatment using the examples non-examples learning model showed a very significant difference in learning outcomes.

Keywords: examples and non-examples learning models, writing news text

\section{A. Pendahuluan}

Pendidikan dan pembelajaran merupakan dua sisi yang berbeda namun saling berhubungan. Pendidikan adalah sebuah lembaga dimana seseorang dapat menerima ilmu pengetahuan sesuai undang-undang yang berlaku. Di dalamnya terdapat guru sebagai tempat atau sarana untuk memberikan pembelajaran. Sedangkan pembelajaran adalah proses dimana terdapat interaksi antara guru dengan murid di dalam kelas, interaksi yang dimaksud adalah seorang guru mentransfer atau memberi stimulus kepada peserta didik berupa ilmu pengetahuan dan pengalaman yang dapat membentuk karakter peserta didik. Pembelajaran merupakan salah satu rangkaian dari belajar. Dikatakan pembelajaran apabila ada proses kegiatan belajar mengajar dari guru untuk peserta didik. Pembelajaran dikatakan baik apabila seorang guru dapat menghasilkan sesuatu yang baik dan berkualitas. Jika seorang guru ingin menghasilkan pembelajaran yang baik, maka guru tersebut harus profesional dan dapat menciptakan, mengupayakan proses belajar mengajar yang baik, kreatif, inovatif dan berkualitas.

Dalam Undang-Undang tentang Sistem Pendidikan Nasional pasal 20 Tahun 2010 menjelaskan bahwa pendidikan merupakan usaha sadar dan terencana untuk mewujudkan suasana belajar dan proses pembelajaran agar peserta didik secara aktif mengembangkan potensi dirinya untuk memiliki kekuatan spiritual keagamaan, pengendalian diri, kepribadian, kecerdasan, akhlak mulia, serta keterampilan yang diperlukan dirinya, masyarakat, bangsa dan Negara. Pendidikan nasional adalah pendidikan yang berdasarkan Pancasila dan

Silampari Bisa: Jurnal Penelitian Pendidikan Bahasa Indonesia, Daerah, dan Asing Vol. 1, No. 2, 2018 
Undang-Undang Dasar Negara Republik Indonesia Tahun 1945 yang berakar pada nila agama, kebudayaan nasional Indonesia dan tanggap terhadap tuntutan perubahan zaman.

Salah satu cara untuk mencapai pendidikan Indonesia yang mengantarkan siswa dalam menghadapi tuntutan perubahan zaman yaitu dengan hadirnya pendidikan mata pelajaran Bahasa Indonesia. Dengan bahasa Indonesia diharapkan siswa akan mampu memahami bukan saja dalam menguasai ilmu pengetahuan dengan baik, tetapi menguasai ilmu-ilmu di bidang kemampuan berbicara, mendengarkan, membaca, dan menulis. Khusus untuk kemampuan menulis sebagai kemampuan yang sifatnya produktif dibutuhkan proses pembelajaran yang baik sehingga siswa mampu mencapai kemampuan tersebut. Salah satu kemampuan yang harus dikuasai oleh siswa tingkat SMP yaitu kemampuan menulis teks berita.

Di dalam berita berisikan fakta-fakta atau sebuah peristiwa yang terjadi disekeliling kita. Agar berita tersebut menarik, bermanfaat dan layak dibaca oleh banyak orang maka seorang penulis berita harus memiliki teknik-teknik dalam menulis berita. Konsep berita dan kriteria umum nilai berita berlaku universal. Artinya tidak hanya berlaku untuk surat kabar, tabloid, dan majalah saja, tetapi juga berlaku untuk radio, televisi, film, dan bahkan juga media on line internet. Jadi menulis berita itu bersifat menyeluruh berlaku untuk semua media dan hal yang paling mendasar dalam menulis berita yaitu tujuan menulis berita atau laporan berita yang disampaikan bermanfaaat atau penting bagi khalayak (Sumadiria, 2011:116-119).

Dari hasil observasi lapangan pada siswa kelas VIII SMPN 14 Kota Tangerang siswa masih belum termotivasi untuk menulis teks berita. Hal ini menyebabkan masih banyak siswa yang belum mencapai nilai ketuntatsan minimal yang ditetapkan oleh sekolah. Untuk itu, salah satu cara untuk mengatasi permasalahan rendahnya kemampuan menulis teks berita tersebut yaitu dengan menerapkan model pembelajaran Example Non-Example.

Huda (2014:23) menjelaskan bahwa model Example Non-Example merupakan strategi pembelajaran yang menggunakan gambar sebagai media untuk menyampaikan materi pelajaran. Jadi, dengan gambar dapat membantu 
mendorong siswa untuk belajar berpikir kritis dengan memecahkan permasalahanpermasalahan yang termuat dalam beberapa contoh gambar yang disajikan.

Menurut Hamdayama (2014:97) Example Non-Example merupakan model yang mengajarkan pada siswa untuk belajar mengerti dan menganalisis sebuah konsep. Jadi, Konsep yang dimaksud yakni sebuah pengamatan seseorang agar berpikir kritis dalam memecahkan permasalahan. Kemudian, menurut Hamdani (2011:94) model pembelajaran Example Non-Example adalah metode belajar yang menggunakan contoh-contoh. Contoh- contoh dapat diperoleh dari kasus atau gambar yang relevan dengan kompetensi dasar. Jadi, yang dimaksud contoh yakni berupa gambar yang relevan. Dengan gambar diharapkan dalam pembelajaran dapat bermanfaat secara fungsional bagi semua siswa dan membantu siswa dalam membangkitkan imajinasinya dalam belajar.

Jadi, dari beberapa teori di atas dapat disimpulkan bahwa model Example Non-Example merupakan model yang mengajarkan sebuah konsep melalui media gambar. Dengan menggunakan gambar diharapkan dapat membantu mendorong dan melatih siswa untu berpikir kritis. Selain itu, dengan menggunakan gambar, siswa dapat melatih mencari dan memilih urutan yang logis sesuai dengan materi yang diajarkan. Dengan demikian, dengan penerapan model Example NonExample pada pembelajaran menulis teks berita diharapkan siswa termotivasi dalam memahami konsep menulis teks berita secara kritis dengan langkahlangkah pembelajaran yang sistematis dan logis. Dengan memahami konsep menulis teks berita pada akhirnya siswa akan mampu juga menulis teks berita dengan baik.

Hasil penelitian yang sudah dilakukan oleh Habibah (2016:54) menunjukkan bahwa penggunaan model pembelajaran examples non examples mampu meningkatkan ketuntasan hasil belajar siswa Kelas V SDN 70 Banda Aceh khusunya pada pada materi tokoh-tokoh pergerakan nasional. Dari hasil penelitian ini menjelaskan bahwa model examples non examples memberikan pengaruh terhadap hasil belajar siswa. Akan tetapi, berbeda dengan penelitian yang dilaksakan mencoba melihat pengaruhnya terhadap kemampuan menulis teks berita. Kemudian, model examples non examples juga pernah diteliti oleh 
Mediatati (2017:100) yang hasil penelitiannya menunjukkan bahwa hasil belajar PPKn mampu ditingkatkan dengan menggunakan model examples non examples pada Siswa Kelas VIII-E SMP Negeri 6 Salatiga. Model examples non examples dalam penelitian ini membantu pemahaman konsep dan memberikan motivasi khusus kepada siswa sehingga mampu meningkatkan hasil belajar PPKn.

Model Examples Non Examples juga pernah diteliti oleh Warkintin (2017:14) dengan jenis penelitian eksperimen. Hasil penelitian menunjukkan bahwa terdapat pengaruh metode examples non examples terhadap kemampuan kognitif siswa terutama dalam materi mengenal penggunaan uang sesuai dengan kebutuhan. Hasil penelitian ini memberikan informasi bahwa model Examples Non Examples mampu memberikan motivasi dan pemahaman kepada siswa tentang konsep mengenal penggunaan uang. Dari beberapa hasil penelitian relevan tersebut dapat kita ketahui bahwa model Examples Non Examples belum dilakukan penelitian khususnya yang bertujuan untuk melihat pengaruhnya terhadap kemampuan menulis teks berita pada siswa Kelas VIII SMPN 14 Kota Tangerang.

\section{B. Metode Penelitian}

Penelitian ini menggunakan metode eksperimen. Menurut Sugiyono (2013:107) metode penelitian eksperimen dapat diartikan sebagai metode penelitian yang digunakan untuk mencari pengaruh tertentu terdapat yang lain dalam kondisi yang terkendalikan. Berdasarkan pada pokok permasalahan, maka metode yang digunakan dalam penelitian ini adalah metode quasi eksperimen dengan melakukan pretes dan postes dua kelompok. Jenis metode penelitian eksperimen ini menggunakan disain penelitian Nonequivalent Control Group Design. Dimana kelas eksperimen yang diberi perlakuan dan kelas control tidak diberi perlakuan. Nonequivalent Control Group Design ini hampir sama dengan pretest dan postest kontrol group desain, hanya pada desain ini kelompok eksperimen maupun kontrol tidak dipilih secara random.

Populasi target dalam penelitian ini adalah seluruh siswa SMPN 14 kota Tangerang yakni kelas VIII seluruhnya berjumlah 170 siswa. Kemudian, dalam penelitian ini, sampel diambil dengan cara memilih 2 kelas dengan jumlah 60 dari 
13 kelas, dimana 1 kelas akan dijadikan kelas kontrol dan kelas 1 lagi dijadikan kelas eksperimen, yang dijadikan sampel dalam penelitian adalah kelas VIII A sebagai kelas eksperimen, yaitu kelas yang menggunakan model pembelajaran Examples Non-Examples dan kelas VIII E sebagai kelas kontrol, yaitu kelas yang tidak menggunakan model pembelajaran Examples Non-Examples. Dari anggota sampel yang diteliti, penulis hanya mengambil sampel dari kelas VIII A dengan jumlah 33siswa dan kelas VIII E 34siswa jadi total yang di eliti adalah 67 siswa.

Teknik pengumpulan data dalam penelitian ini menggunakan tes. Pengertian tes menurut menurut Jihad dan Haris (2012:67) tes merupakan himpunan pertanyaan yang harus dijawab, harus ditanggapi, atau tugas yang harus dilaksanakan oleh orang yang dites. Tes yang dilakukan dalam penelitian ini berbentuk esai. Tes dilakukan untuk mengetahui sejauh mana peserta didik dapat menulis berita dengan menggunakan model pembelajaran Examples nonExamples. Sebelum tes diberikan kepada siswa maka diuji validitas dan reliabilitasnya. Kemudian, teknik analisis data dimulai dari uji normalitas, uji homogenitas, kemudian dilanjutkan dengan uji hipotesis.

\section{Hasil Penelitian dan Pembahasan}

\section{Hasil Penelitian}

a. Pengujian Persyaratan Analisis Data

1) Uji Normalitas Data Pretes Kelas Kontrol dan Kelas Eksperimen

a) Uji Normalitas Data Pretes Kelas Kontrol

Salah satu syarat harus ditempuh untuk melakukan uji $t$ adalah uji kenormalitasan data. Dalam uji kenormalitasan data ini peneliti menggunakan uji normalitas chi kuadrat. Dengan ketentuan jika $x 2$ hitung $<x 2$ tabel dapat disimpulkan bahwa data berdistribusi normal. Dari perhitungan uji normalitas chi kuadrat data pretes kelas kontrol diperoleh $\times 2$ hitung 6.39 jika nilai tersebut dikonsultasikan dengan $\times 2$ tabel (0.05: k-1) maka diperoleh $\times 2$ tabel 11,07. Karena $x 2$ hitung $<x 2$ tabel $=6.39<11,08$. Dapat disimpulkan bahwa data pretes kelas kontrol berdistribusi normal. 
b) Uji Normalitas Data Pretes Kelas Eksperimen

Dari perhitungan uji normalitas chi kuadrat data pretes kelas eksperimen maka diperoleh $\times 2$ hitung 7,78 jika nilai tersebut dikonsultasikan dengan $x 2$ tabel (0.05: k-1) maka diperoleh $\times 2$ tabel 11,07. Karena $\times 2$ hitung $<\times 2$ tabel $=7,78<$ 11,07. Dapat disimpulkan bahwa data pretes kelas kontrol berdistribusi normal. Untuk lebih jelasnya dapat dilihat pada tabel di bawah ini :

Tabel 1. Uji Normalitas Data Pretes Kelas Kontrol dan Eksperimen

\begin{tabular}{|c|c|c|c|}
\hline Kelas & $\chi^{2}$ hitung & $\chi^{2}$ tabel & Klasifikasi \\
\hline Kontrol & 6.39 & 11,07 & Normal \\
\hline Eksperimen & 7,78 & 11,07 & Normal \\
\hline
\end{tabular}

2) Uji Normalitas Data Postes Kelas Kontrol dan Kelas Eksperimen

a) Uji Normalitas Data Postes Kelas Kontrol

Salah satu syarat harus ditempuh untuk melakukan uji $t$ adalah uji kenormalitasan data. Dalam uji kenormalitasan data ini peneliti menggunakan uji normalitas chi kuadrat. Dengan ketentuan jika $\times 2$ hitung $<\times 2$ tabel dapat disimpulkan bahwa data berdistribusi normal. Dari perhitungan uji normalitas chi kuadrat data postes kelas kontrol diperoleh $\times 2$ hitung 3,98 jika nilai tersebut dikonsultasikan dengan $\times 2$ tabel (0.05: k-1) maka diperoleh $\times 2$ tabel 11,07. Karena $\times 2$ hitung $<\times 2$ tabel $=3,98<11,07$. Dapat disimpulkan bahwa data postes kelas kontrol berdistribusi normal.

b) Uji Normalitas Postes Kelas Eksperimen

Dari perhitungan uji normalitas chi kuadrat data postes kelas eksperimen maka diperoleh $\times 2$ hitung 5,21 jika nilai tersebut dikonsultasikan dengan $x 2$ tabel (0.05: k-1) maka diperoleh $\times 2$ tabel 11,07.

Karena $x 2$ hitung $<$ X 2 tabel $=5.21<11,07$. Dapat disimpulkan bahwa data pretes kelas eksperimen berdistribusi normal. Untuk lebih jelasnya dapat dilihat pada tabel di bawah ini :

Tabel 2. Uji Normalitas Data Postes Kelas Kontrol dan Kelas Eksperimen

\begin{tabular}{|c|c|c|c|c|c|}
\hline Kelas & $\overline{\mathrm{x}}$ & $\mathrm{N}$ & Fhitung & Ftabel & Klasifikasi \\
\hline Eksperimen & 60,97 & 30 & 1,50 & 1,85 & Homogen \\
\hline Kontrol & 59,9 & 30 & 1,50 & 1,85 & Homogen \\
\hline
\end{tabular}

Silampari Bisa: Jurnal Penelitian Pendidikan Bahasa Indonesia, Daerah, dan Asing Vol. 1, No. 2, 2018 
2) Uji Homogenitas Data Pretes dan Postes Kelas Kontrol dan Kelas Eksperimen

a) Uji Homogenitas Data Pretes Kelas Kontrol dan Eksperimen

Dari hasil pengujian uji homogenitas data pretes kelas kontrol dan kelas eksperimen dengan menggunakan uji fisher (uji $F$ ) maka diperoleh $F$ hitung 1.50 jika nilai tersebut dikonsultasikan dnegan $\mathrm{F}$ tabel $(0,05 ;(\mathrm{nA}-1) /(\mathrm{ng}-1))$ diperoleh $F$ tabel 1,85. Karena $F$ hitung $<F$ tabel $=1.50<1,85$ dapat disimpulkan bahwa kedua sampel berasal dari populasi yang homogen. Untuk lebih jelasnya dapat dilihat pada tabel di bawah ini :

Tabel 3. Uji Homogenitas Fisher Data Pretes Kelas Kontrol dan Eksperimen

\begin{tabular}{|c|c|c|c|c|c|}
\hline Kelas & $\overline{\mathrm{x}}$ & $\mathrm{N}$ & $\mathrm{F}_{\text {hitung }}$ & $\mathrm{F}_{\text {tabel }}$ & Klasifikasi \\
\hline Eksperimen & 60,97 & 30 & 1,50 & 1,85 & Homogen \\
\hline Kontrol & 59,9 & 30 & 1,50 & 1,85 & Homogen \\
\hline
\end{tabular}

b) Uji Homogenitas Data Postes Kelas Kontrol dan Eksperimen

Dari hasil pengujian uji homogenitas data postes kelas kontrol dan kelas eksperimen dengan menggunakan uji fisher (uji $F$ ) maka diperoleh $F$ hitung 1.18 jika nilai tersebut dikonsultasikan dnegan $\mathrm{F}$ tabel $(0,05 ;(\mathrm{nA}-1) /(\mathrm{ng}-1))$ diperoleh $F$ tabel 1,85 . Karena $F$ hitung $<F$ tabel $=1,18<1,85$ dapat disimpulkan bahwa kedua sampel berasal dari populasi yang homogen. Untuk lebih jelasnya dapat dilihat pada tabel di bawah ini:

Tabel 4. Uji Homogenitas Fisher Data Postes Kelas Kontrol dan Eksperimen

\begin{tabular}{|c|c|c|c|c|c|}
\hline Kelas & $\mathrm{x}$ & $\mathrm{N}$ & $\mathrm{F}_{\text {hitung }}$ & $\mathrm{F}_{\text {tabel }}$ & Klasifikasi \\
\hline Eksperimen & 72.63 & 30 & 1,18 & 1,85 & Homogen \\
\hline Kontrol & 62,97 & 30 & 1,18 & 1,85 & Homogen \\
\hline
\end{tabular}

\section{Pembahasan}

Berdasarkan perhitungan data hasil penelitian maka, dapat diperoleh nilai rata-rata pretes kelas eksperimen yaitu (60.97), dan nilai rata-rata pretes kelas kontrol $(59,9)$, adapun pada postes, nilai rata-rata kelas eksperimen yaitu $(72,63)$, dan nilai rata-rata kelas kontrol yaitu $(62,97)$, dari pernyataan tersebut dapat dinyatakan bahawa pada pretes hasil belajar menulis teks berita siswa antara kelas eksperimen dengan kelas kontrol tidak memiliki perbedaan yang jauh, meskipun nilai rata-rata kelas eksperimen lebih tinggi jika dibandingkan dengan nilai rata-rata kelas kontrol. Hal ini membuktikan bahwa model example non- 
example mampu memotivasi dan memberikan pemehaman kepada siswa tentang suatu konsep. Hal ini sesuai dengan penelitian relevan yang dilakukan oleh Mediatati (2017:100) Warkintin (2017:14) bahwa model pembelajaran examples non-examples mampu mempengaruhi hasil belajar siswa terutama pada aspek konsep dan keterampilan.

Begitupun pada postes, didapatkan nilai rata-rata kelas eksperimen mengalami kenaikan jika dibandingkan dengan nilai rata-rata kelas kontrol. Hal ini cukup dijadikan bukti bahwa pembelajaran dengan menggunakan model pembelajaran examples non-examples di kelas eksperimen mampu meningkatkan hasil belajar menulis teks berita siswa. Untuk memperkuat pendapat tersebut, maka dilakukan uji hipotesis.

Hasil dari uji hipotesis data pretes menunjukkan thitung $=0,5283<$ ttabel 2,0021, sementara hasil dari uji hipotesis dari postes menunjukkan thitung $=$ $2,1146>$ ttabel $=2,0021$, maka sesuai dengan pendapat diatas bahwa pada pretes tidak terdapat perbedaan yang signifikan terhadap kemampuan menulis teks berita. Beda dengan siswa yang mendapatkan pembelajaran dengan menggunakan model pembelajaran examples non-examples dengan siswa yang tdak mendapatkan pembelajaran examples non-examples.

Pembelajaran yang menggunakan model pembelajaran examples nonexamples di kelas eksperimen, mendapatkan nilai-nilai lebih tinggi dari pada kelas kontrol yang tidak medapatkan pembelajaran examples non-examples. Hal ini dapat dilihat dari model pembelajaran yang diberikan, karena pembelajaran dengan menggunakan model pembelajaran examples non-examples siswa akan lebih fokus dan teratur, karena pada pembelajaran examples nonexamples ini siswa di pusatkan perhatiannya terhadap gambar yang diberikan jadi mereka lebih fokus belajaranya. Sehingga dapat memudahkan siswa untuk menulis teks berita.

Lain lagi dengan kelas kontrol yang tidak mengguankan model pembelajaran examples non-examples. Pada kelas kontrol ini, selama pembelajaran berlangsung guru hanya menjelaskan materi yang akan dipelajari. Siswa kelas kontrol ini mendengarkan dan mencatat apa yang telah disampaikan oleh guru. Ketika guru memerintahkan siswa untuk menulis teks berita. 
Dengan menggunakan model pembelajaran tersebut, siswa dapat mencapai nilai yang lebih baik lagi dalam pembelajaran menulis teks berita. Maka dari itu, dengan menggunakan model pembelajaran examples nonexamples, akan mempermudah siswa untuk menulis. Model pembelajaran examples nonexamples juga menampilkan sebuah gambar sehingga siswa lebih mudah mengerti dengan materi berita yang diajarkan guru.

Dari pembahasan ini dapat menyimpulkan bahwa terdapat pengaruh penggunaan model pembelajaran examples non-examples terjadap hasil belajar menulis teks berita. Penggunaan model pembelajaran examples non-examples ini mampu meningkatkan hasil belajar menulis teks berita siswa. Akan tetapi, peneliti menyadari bahwa penelitian ini tidak sepenuhnya sampai pada tingkat kebenaran mutlak atau tidak terlepas dari kekurangan. Salah satu yang menjadi penyebabnya ialah keterbatasan waktu, biaya, dan kemampuan peneliti untuk meneliti lebih dalam lagi. Oleh karena itu, peneliti mengharapkan ada peneliti selanjutnya dengan tinjauan yang lebih luas.

\section{Simpulan}

Hasil belajar menulis teks berita siswa SMPN 14 Kota Tangerang pada kelas eksperimen setelah diberi perlakuan yaitu dengan menggunakan model pembelajaran examples non-examples menunjukan bahwa nilai rata rata kelas eksperimen 70-78. Maka, dapat disimpulkan bahwa hasil belajar kelas eksperimen setelah menggunakan model pembelajaran examples non-examples memiliki hasil yang signifikan dan penggunaan model pembelajaran examples non-examples dapat mempengaruhi hasil belajar menulis teks berita siswa. Hasil pegujian ini sekaligus membuktikan bahwa terjadi perbedaan hasil belajar menulis teks berita, dikarenakan perbedaan perlakuan yang diberikan kepada kelas kontrol dan kelas eksperimen. 


\section{Daftar Pustaka}

Habibah, Syarifah. (2016). Penggunaan Model Pembelajaran Examples Non Examples terhadap Ketuntasan Hasil Belajar Siswa pada Materi TokohTokoh Pergerakan Nasional Kelas V SDN 70 Banda Aceh. Jurnal Pesona Dasar, 3 (4), http://www.jurnal.unsyiah.ac.id/PEAR/article/view/7541

Hamdani. (2011). Strategi Belajar Mengajar. Bandung: CV Pustaka Setia.

Hamdayama, Jumanta. (2014). Model dan Metode Pembelajaran Kreatif dan Berkarakter. Bogor: Ghalia Indonesia.

Huda, Miftahul. (2014). Model-Model Pengajaran dan Pembelajaran. Yogyakarta: Pustaka Pelajar.

Jihad, Asep dan Haris, Abdul. (2012). Evaluasi Pembelajaran. Yogyakarta: Multi Pressindo Yogyakarta.

Mediatati, N. (2017). Meningkatkan Hasil Belajar PPKn Menggunakan Model Pembelajaran Examples Non Examples pada Siswa Kelas VIIIE SMP Negeri 6 Salatiga. Journal of Education Research and Evaluation, 1(2), 100. doi:10.23887/jere.v1i2.10073

Sugiyono. (2015). Statistika untuk Penelitian. Bandung: Alfabeta.

Sumadiria, AS Haris. (2011). Jurnalistik Indonesia Menulis Berita dan Feature Panduan Praktis Jurnalis Profesional. Bandung: Simbiosa Rekatama Media.

Warkintin, W. (2017). Pengaruh Metode Pembelajaran Examples Non Examples terhadap Kognitif Siswa pada Materi Mengenal Penggunaan Uang Sesuai dengan Kebutuhan. JPDI (Jurnal Pendidikan Dasar Indonesia), 1(1), 14. doi:10.26737/jpdi.v1i1.116 